\title{
As narrativas jornalísticas em formato de stories no Instagram e Snapchat
}

\author{
The journalistic narratives in stories format on Instagram and
}

Snapchat

\author{
Yago Modesto Alves, Universidad Federal do Tocantis, Brasil \\ yagoma07@gmail.com | http://orcid.org/0000-0001-5562-9891 \\ Quadra 109 Norte, Av. NS15, ALCNO-14 Plano Diretor Norte-TO, Brasil \\ Dra. Edna de Mello Silva, Universidad Federal do São Paulo, Brasil \\ prof.ednamello@gmail.com | http://orcid.org/0000-0003-1312-9041 \\ Rua Sena Madureira-1500 4 andar (UAB) Vila Clementino, São Paulo-SP Brasil
}

\begin{abstract}
Resumo
A presente pesquisa tem como temática a apropriação pelo jornalismo nas mídias sociais que tem como base a publicação de mensagens em formato de imagens instantâneas, especificamente o Snapchat e o Instagram Stories. O estudo se justifica pela ascensão do uso das mídias sociais no jornalismo, por conta do público que tende cada vez mais a consumir informação neste tipo de espaço. Sabendo que veículos jornalísticos, nacionais e internacionais, originários de mídias tradicionais ou da internet, têm perfis ativos nessas mídias, surge a pesquisa aqui apresentada, que objetiva propor e caracterizar as tipologias de narrativas jornalísticas em formato de Stories. Em sua parte teórica, o artigo disserta sobre o contexto geral de apropriação das mídias sociais pelo jornalismo; as características e particularidades dos aplicativos Snapchat e Instagram e as principais formas de apropriação das mídias sociais pelo jornalismo. Para cumprir o objetivo, são utilizadas técnicas específicas da análise de conteúdo, a partir dos procedimentos metodológicos propostos por Bardin (2009); e da análise descritiva, segundo as proposições de Lopes (2003). Por meio da observação e categorização, identifica e caracteriza nove tipos de narrativas jornalísticas em formato de Stories: Narrativa Textual; Textual Hipermidiática; Chamada Hipermidiática; Convite; Convite Hipermidiática; Jornalista Selfie; Nota; Entrevista; e Múltiplos Formatos. A partir das análises e descrições, aponta que essas narrativas são uma adaptação das narrativas jornalísticas tradicionais às potencialidades e limitações do Instagram e Snapchat, com elementos da reportagem, da notícia, lead, entrevista, nota, chamada, dentre outros.
\end{abstract}




\begin{abstract}
:
The present research has as its theme the appropriation by journalism in social media that is based on the publication of messages in format of instant images, specifically Snapchat and Instagram Stories. The study is justified by the rise of the use of social media in journalism, because of the public that tends more and more to consume information in this type of space. Knowing that journalistic medias, national and international, originating in traditional media or the Internet, have profiles active in these media, the research presented here aims to propose and characterize the typologies of journalistic narratives in Stories format. In its theoretical part, the article discusses the general context of appropriation of social media by journalism; the characteristics and particularities of the Snapchat and Instagram applications and the main forms of appropriation of social media by journalism. To fulfill the objective, specific techniques of content analysis are used, based on the methodological procedures proposed by Bardin (2009); and descriptive analysis, according to the propositions of Lopes (2003). Through observation and categorization, it identifies and characterizes nine types of journalistic narratives in Stories format: Textual Narrative; Textual Hypermedia; Hypermedia call; Invitation; Hypermiditic Invitation; Journalist Selfie; Note; Interview; and Multiple Formats. From the analysis and descriptions, the article points out that these narratives are an adaptation of the traditional journalistic narratives to the potentialities and limitations of Instagram and Snapchat, with elements of reporting, news, lead, interview, note, call, among others.
\end{abstract}

Palavras chave: Mídias Sociais, Snapchat, Instagram Stories.

Keywords: social Media, Snapchat; Instagram Stories.

\title{
1. INTRODUÇÃO
}

Se as mídias sociais têm transformado a vida social das pessoas, não seria diferente que intervisse também no lado profissional dos jornalistas, que se viram diante de novos recursos informativos para a construção das notícias, principalmente por conta de uma linguagem própria e propriedades comunicativas e de conteúdo que difere essas mídias dos meios tradicionais (Herrero-Curiel, 2012; Mendéz, 2012).

Tornando-se cada vez mais comum as pessoas estarem conectadas em uma mídia social, o jornalista começa a estar mais atento às tendências e movimentos presentes ou originados nesse ambiente. É o que vem acontecendo com um tipo de aplicativo que emergiu ao público nos últimos dois anos, e que tem como base a publicação de mensagens em formato de imagens instantâneas, que "desaparecem" na tela após poucos segundos de visualização. O Snapchat foi o pioneiro das chamadas mídias sociais de imagens instantâneas, também conceituadas como mídias sociais efêmeras (Bayer et al, 2015).

Criado por Evan Spiegel, Bobby Murphy e Reggie Brown, o Snapchat tem como principal característica a possibilidade de tirar fotos, gravar vídeos, adicionar textos ou desenhos à imagem e, por fim, escolher o tempo que ela ficará disponível na tela de um amigo de sua lista. O tempo 
máximo para cada snap, como são chamadas as publicações nessa mídia, são de 10 segundos. Com seu crescimento, outros aplicativos, já consolidados em suas propostas de postagem de conteúdo, passaram a disponibilizar funcionalidades baseadas nesse mesmo formato de conteúdo. O mais popular é o Instagram, mídia social voltada, primeiramente, ao compartilhamento de fotos e vídeos entre seus usuários em uma linha do tempo. Desde agosto de 2016, passou a disponibilizar a funcionalidade Instagram Stories, com as mesmas características do Snapchat.

A presente pesquisa tem como temática a apropriação pelo jornalismo nesses dois aplicativos. $O$ objetivo é propor e caracterizar nove tipologias de narrativas jornalísticas em formato de Stories, que é o espaço disponibilizado nas duas ferramentas para a publicação de mensagens em imagens instantâneas. Antes disso, apresenta o contexto de relação do jornalismo com as mídias sociais, as principais formas de apropriação, bem como as particularidades e características das Stories no Instagram e Snapchat. Posteriormente, discorre os procedimentos metodológicos utilizados na pesquisa e, por fim, propõe nove tipologias de narrativas, suas características e classificações.

O estudo se justifica pela ascensão do uso das mídias sociais no jornalismo, já que o público tende cada vez mais a consumir informação neste tipo de espaço virtual. Outro fator é a necessidade de pesquisas que entendam o que esses ambientes têm a oferecer para o mercado jornalístico, tanto nas formas de consumo quanto de produção da notícia.

\section{JORNALISMO E MÍDIAS SOCIAIS}

Como afirmam Kaplan e Haenlein (2009), as mídias sociais representam uma nova tendência de interesse às organizações que operam no ambiente on-line. No caso específico do jornalismo, os veículos que já estavam presentes nos sites de notícias, passam a criar perfis nas redes sociais para compartilhar notícia para os usuários do meio. Para García de Torres et al (2011), esses espaços se tornam imprescindíveis para o jornalista conseguir informação, disseminar notícias, chegar aos leitores localizados em regiões distantes e alcançar os jovens ou aqueles que não consumem jornalismo no formato tradicional. Assim, inovar acaba sendo essencial para se adaptar a este cenário.

Veículos de mídias tradicionais já consolidados no mercado jornalístico se veem diante de transformações que têm provocado mudanças também em suas estruturas organizacionais. Com o objetivo de atender a nova demanda, as empresas passam a chegar ao público de maneira mais dinâmica, com informação local, ubíqua, portátil e em tempo real. As mídias sociais se tornam o ambiente propício para alcançar esses objetivos, por promover a facilidade na criação de conteúdo, dar várias possibilidades para o produtor interagir com o público, e principalmente, integrar às mensagens novas narrativas com estruturas que podem conquistar ainda mais os usuários (Flores-Vivar, 2012).

Essas narrativas vão além do texto e imagens. Para Flores-Vivar (2012), a grande novidade está na mudança e emersão de códigos comunicativos, que evoluem na medida em que se 
desenvolvem as tecnologias e aplicativos digitais. Os jornalistas precisam entender os formatos e aplicabilidades digitais como ferramentas que permitem a potencialização do conteúdo noticioso, para, posteriormente, ganhar reconhecimento na rede e alcançar o interesse do público. O novo perfil desses profissionais acaba sendo o de contador de histórias em novos formatos.

Pode-se, portanto, destacar que a relação que o jornalismo tem mantido com as mídias sociais é de mútuo enriquecimento, principalmente no que diz respeito à produção e compartilhamento de conteúdo. Algumas características do webjornalismo, presentes nos sites de notícias, são potencializadas no momento em que os veículos passam a produzir ou disponibilizar conteúdo para ferramentas de mídias sociais. Dentre as potencialidades, Pacheco (2014) destaca:

Ferramentas multimídias: ali, os jornalistas podem disponibilizar conteúdos audiovisuais, como fotos e vídeos na própria ferramenta do ambiente, simplificando a estrutura da informação, já que é desnecessário abri-los em outro site;

Hipertextualidade: conjuntamente à produção de um conteúdo novo, bem como na transposição da notícia, é possível a disponibilização de hiperlinks que vinculem aquele conteúdo com o publicado no site do veículo;

Interação: estabelecida principalmente através dos comentários dos seguidores/público;

Dinamismo no conteúdo: O contraste entre a fonte e o fundo utilizado na concepção de redes sociais permite uma melhor visualização para o usuário, facilitando a leitura das informações propagadas por essas plataformas.

Capacidade de atualização contínua: o conteúdo pode ser disponibilizado e atualizado segundos após o acontecimento do fato.

Os espaços de Stories das mídias sociais Snapchat e Instagram proporcionam aos jornalistas a produção de conteúdo que atendem as potencialidades destacadas pelos autores citados acima. Mas, em contra partida, apresenta alguns desafios devido a características próprias relacionadas, principalmente, a efemeridade e falta de memória, como é exposto no tópico a seguir.

\section{PARTICULARIDADES DAS MÍDIAS SOCIAIS DE IMAGENS INSTANTÂNEAS}

Há uma série de características que fazem as mídias sociais de imagens instantâneas aguçarem a atenção dos veículos de mídia para a produção de conteúdo. Bradshaw e Maseda (2016) apresentam dicas para o uso jornalístico do Snapchat, que podem ser ampliadas ao Stories do Instagram por conta de características semelhantes entre os dois aplicativos. Para eles, na grande lista de desafios que os jornalistas têm enfrentado com o desenvolvimento das novas tecnologias, as Stories seja a mais frustrante de todas. Ao mesmo tempo em que prometem altos níveis de audiência e incríveis índices de promoção de conteúdo, há dificuldades que são enfrentadas. Dentre elas, destacam-se: 
A natureza efêmera da ferramenta: A efemeridade é algo inerente à notícia jornalística, porém, nos aplicativos como Snapchat e Instagram Stories, ela é potencializada a um nível que transcende a forma de consumo de conteúdo dos outros meios de comunicação. Tal contexto se intensifica quando somado à falta de memória do conteúdo publicado no aplicativo.

Interface desses aplicativos: A interatividade no consumo do conteúdo se dá exclusivamente através do toque na tela. Caso a imagem não seja interessante, basta um toque para pular de cena, ou deslizar a tela para pular de perfil.

O amadorismo do conteúdo que é produzido para essas plataformas: As imagens produzidas nesses aplicativos podem dar um caráter de amadorismo ao produtor, por conta da tipografia das fontes de texto bem como os pinceis de desenho.

Diante desses pontos, para os autores, pode parecer difícil pensar que as características do Snapchat e Instagram Stories possam entusiasmar aqueles que pretendem dedicar a contar histórias de forma profissional nesses ambientes. Mas a potencialidade de audiência desses aplicativos faz com que os desafios sejam enfrentados e que os jornalistas comecem a pensar essas mídias sociais como poderosas ferramentas narrativas, não oferecidas, até então, por nenhuma outra plataforma de mídia.

Jungblut (2017) vê as dificuldades apontadas por Bradshaw e Maseda (2016) como pontos fortes para produção de conteúdo nas Stories. Para ela, os apps de mídias sociais de imagens instantâneas se popularizaram por conta de suas particularidades: imagens que somem depois de um tempo, amadorismo de seu conteúdo e a possibilidade de construir fotos e vídeos de uma forma mais autêntica. Tais singularidades acabaram por introduzir um vício de compartilhamento entre as pessoas. Dentre os motivos para apostar em conteúdo nas Stories, Jungblut (2017) destaca:

Criação passiva de conteúdo: Para criar uma story basta ser criativo, não precisa de muita produção nem imagens bem trabalhadas ou editadas.

Laboratório de ideias: Como o conteúdo não fica exposto por muito tempo na rede, o usuário pode fazer testes até encontrar a melhor forma de construir narrativas interessantes ou para conquistar um novo público. Assim, caso aquela tentativa seja bem acolhida pelo público, o produtor do conteúdo pode publicar aquele formato narrativo outras vezes.

Variedade de recursos: É possível desenhar, colar adesivos (stickers), filtros, localização, marcar usuários, etc.

Reverberação do conteúdo: A possibilidade de adicionar links às postagens faz com que as Stories sejam um espaço para que o usuário trafegue os sites de notícias ${ }^{1}$. 
Compreendido as características desses aplicativos, partem-se agora as formas gerais de apropriação pelo jornalismo das mídias sociais. Como será visto a seguir, o enfoque da difusão será útil para identificar e caracterizar as tipologias de narrativas propostas nesta pesquisa.

\section{FORMAS DE APROPRIAÇÃO DAS MÍDIAS SOCIAIS PELO JORNALISMO}

Estudos buscam explorar as formas de apropriações e possibilidades que as mídias sociais têm proporcionado às práticas jornalísticas, incluindo a produção, construção e principalmente a distribuição e consumo da notícia. Os tipos de relações das mídias e redes sociais com o jornalismo, propostas por Rost (2012), por exemplo, se convergem em alguns pontos com as ideias de Recuero (2012) e Hermida (2012). O quadro 1 traz a convergência das ideias dos três autores, e, em seguida, são exploradas cada uma delas.

Quadro 1 - Enfoque do uso jornalístico nas mídias sociais

\begin{tabular}{|l|l|l|}
\hline \multicolumn{1}{|c|}{ Rost (2012) } & \multicolumn{1}{|c|}{ Hermida (2012) } & \multicolumn{1}{c|}{ Recuero (2012) } \\
\hline \multirow{2}{*}{ Recepção } & $\begin{array}{l}\text { Coletar ou conseguir infor- } \\
\text { mações }\end{array}$ & Fontes produtoras de informação \\
\hline \multirow{2}{*}{ Difusão } & Reportar notícias & \\
\cline { 2 - 3 } & Recomendar as notícias & $\begin{array}{l}\text { Espaço de reverberação das } \\
\text { informações. }\end{array}$ \\
\hline Interação & & \\
\hline
\end{tabular}

Fonte: Elaborado pelos autores

No primeiro caso, é possível enxergar as mídias sociais desde o aspecto da recepção. O conteúdo produzido pelos usuários de um site de rede social pode servir de fonte ou pauta para os jornais. Como a internet faz parte da rotina produtiva dos jornalistas, esse espaço é aproveitado para encontrar histórias, ideias e fontes, realidade que tem se intensificado com o uso das mídias sociais. Um veículo pode utilizar de conversas, vídeos, fotos, postagens ou depoimentos dos usuários sobre um assunto que está sendo pautado pela imprensa, acima de tudo, em situações em que o jornalista não está presente (Rost, 2012; Hermida, 2012).

O segundo enfoque busca analisar o poder de difusão de conteúdos que as mídias sociais têm como meio de comunicação, e é a partir dele que se pode entender as narrativas jornalísticas em formato de Stories. Hermida (2012) subdivide as formas de difusão em: reportar as notícias e recomendar as notícias. Recuero (2012) não trata especificamente o uso das mídias sociais para reportar notícias, mas no caso da recomendação, a autora a vê como filtro e reverberação de informações.

Assim como os jornalistas produzem conteúdos para serem publicados no jornal, na revista, rádio, televisão ou sites de notícias, eles também passam a criar conteúdo exclusivamente para 
as mídias sociais. Eles podem apropriar-se desses espaços tanto para ampliar a reportagem de um acontecimento já divulgado em outro meio, como também para produzir conteúdo de assuntos inéditos e específicos para cada site ou aplicativo. Este tipo de apropriação ainda é recente, uma vez que, quando as mídias sociais se popularizaram, era comum apenas a filtragem de informação, postagem de links de notícias publicadas dos sites jornalísticos. Mas, com as potencialidades desses espaços, que crescem a cada nova atualização, o jornalismo começa a encontrar mais um ambiente para reportar a notícia (Hermida, 2012).

Outra maneira de se utilizar as mídias sociais para difusão é a recomendação de informações, que consiste na publicação de links de matérias divulgadas na íntegra no site de notícias do veículo. Segundo Recuero (2012), a atuação das redes sociais na filtragem de informações é o caso mais comum observado na relação RSI com o jornalismo, em termos de difusão de informações. Os links das notícias publicadas nos sites jornalísticos são compartilhados tanto pelos próprios perfis ou páginas oficiais dos veículos quanto do público. Para Hermida (2012), esse tipo de apropriação é útil para promover conteúdo, aumentar o alcance do público e acessos no site de notícias, além de potencializar o nome do veículo de comunicação.

Por fim, Rost (2012) traz a interação como outro enfoque do uso jornalístico das mídias sociais. Neste caso, elas são vistas como um ambiente de comunicação entre os veículos e imprensa, leitores, fontes e outros jornalistas.

\section{PROCEDIMENTOS METODOLÓGICOS}

O grande desafio de pesquisar as apropriações pelo jornalismo nas mídias sociais de imagens instãntaneas é que seu conteudo não fica disponível no meio, ou seja, não há memoria nesses espaços. A perenidade ou capacidade de memória é uma das grandes características do jornalismo na web, que o potencializa ainda mais em relação aos outros meios de comunicação. Isso porque, na internet, o material jornalístico pode ser guardado indefinidamente, em grande quantidade e em pouco espaço, com um custo relativamente barato em relação aos outros meios. Nas mídias sociais tradicionais, como Facebook e Twitter, a memória característica da internet ainda está eficazmente presente, pois seu conteúdo fica disponibilizado na linha do tempo do usuário. A situação é distinta quando se trata das mídias exploradas nessa pesquisa. O conteúdo do Snapchat e do Instagram Stories só está disponível no aplicativo durante 24 horas, dificultando o processo de coleta e análise do que é ali compartilhado.

Metodologicamente, essa pesquisa se caracteriza por um estudo de caráter descritivo-analítico, com abordagem qualitativa. Os procedimentos metodológicos foram divididos, para fins esquemáticos, nas quatro fases metodológicas das pesquisas em comunicação propostas por Lopes (2003), são elas: 1) Definição do objeto; 2) Observação; 3) Descrição; 4) Interpretação. Essas fases convergiram com os polos cronológicos de organização da análise de conteúdo segundo Bardin (2009), são eles: 1) Pré-análise; 2) Exploração do material e 3) Tratamento dos resultados, inferência e interpretação. Segundo Bardin (2009), a análise de conteúdo contempla 
um conjunto de procedimentos de análise das comunicações, utilizando técnicas sistemáticas e objetivas de descrição do conteúdo da mensagem.

Primeiramente, foi criado um perfil nos dois aplicativos, Snapchat e Instagram, para a coleta do material analisado. Depois, foram elencados os principais veículos jornalísticos de Televisão, Impresso (Revista e Jornal) e Internet, do Brasil, Estados Unidos, países da Europa, Ásia e América Latina, levando em conta, principalmente, a audiência desses veículos ${ }^{2}$. Posteriormente, foi realizada a procura do perfil desses veículos na mídia social Instagram. Através da funcionalidade Sugestões ${ }^{3}$, foram feitas buscas por outros perfis jornalísticos no aplicativo. Em seguida, realizouse a busca no Snapchat pelos perfis dos veículos anteriormente localizados no Instagram Stories.

A coleta deu-se durante os 31 dias do mês de Outubro de 2017, em sete perfis jornalísticos que publicaram no Snapchat e 32 que fizeram postagens no Instagram Stories. Como, na época em que foi feita, o conteúdo publicado nessas mídias sociais não era disponibilizado em algum tipo de memória no próprio aplicativo, foi realizada uma coleta, entre às $23 \mathrm{~h}$ e $1 \mathrm{~h}$ do dia seguinte. No Instagram Stories, foi utilizado o aplicativo StorySaver, que, vinculado a uma conta do Instagram, disponibiliza todas as fotos e vídeos publicados na Stories dos perfis que a pessoa segue. Por conta de o Snapchat impossibilitar o salvamento de vídeos postados na rede, foi utilizado o aplicativo AZ Screen Record. Este permite a captura de tela em vídeo do celular enquanto os snaps são reproduzidos. No fim da gravação, é disponibilizado um vídeo da reprodução da tela. Levando em conta o número de dias em que foram feitas as postagens e as particularidades no tipo de conteúdo publicado pelo veículo, foram seleccionados 12 perfis jornalísticos para a etapa posterior.

O passo seguinte foi a categorização a partir de uma observação e descrição do conteúdo do material coletado. A descrição é uma operação desenvolvida através da análise descritiva, e segundo Lopes (2003, p.149) é feita em dois passos: O primeiro é a organização, crítica e classificação dos dados coletados. O segundo abrange "procedimentos propriamente analíticos, que visam à construção de objetos empíricos e a reprodução do fenômeno nas condições de sua produção".

Um quadro foi criado para inserir a descrição de cada dia de postagem nos perfis selecionados. Foram indicados os tipos de narrativas presentes na sequência de postagem daquele dia; a descrição de como ela está sendo apresentada; os recursos jornalísticos; os recursos das mídias sociais utilizados pelos veículos; e outras observações relevantes. A sistematização da descrição de cada dia de postagem, em todos os dias em que houve publicações dos perfis nas respectivas mídias sociais, foi útil para identificar particularidades e generalidades nas postagens dos perfis jornalísticos.

Após descritas, todas as postagens diárias dos perfis selecionados foram agrupadas segundo as semelhanças do tipo de mídia utilizado no conteúdo. Foi observada a sequência de postagens de cada um dos dias em que o material foi coletado, identificando cinco tipos de categorias: 1) Sequência de postagens apenas com vídeos (V); 2) Sequência de postagens apenas com fotos 
(F); 3) Sequência de postagens com vídeos e fotos (VF); 4) Sequência de postagens em que os vídeos mostram o jornalista na cena (VJ); 5) Sequência de postagens com fotos e vídeos com o jornalista presente em cena (VFJ).

As postagens que apresentaram as mesmas categorias foram agrupadas novamente, partindo da hipótese de que os elementos da publicação estariam relacionados com o tipo de narrativa utilizada, proposição essa que foi confirmada posteriormente. No grupo de postagens de cada uma dessas categorias, foram observados, ainda, outros elementos característicos das postagens, como: uso de hiperlinks, características próprias do texto narrativo e elementos do jornalismo, como a entrevista, nota e reportagem. O quadro 2 ilustra como as categorias e as características foram utilizadas para identificar as narrativas.

Quadro 2 - Categorias presentes em cada Narrativa

\begin{tabular}{|l|c|c|}
\hline \multicolumn{1}{|c|}{ Tipo de Narrativa } & Categorias & Outras Características \\
\hline Narrativa Textual & F; V; VF & Texto das legendas em formato de notícia. \\
\hline Narrativa Textual Hipermidiática & F; V; VF & Texto das legendas em formato de notícia e \\
hiperlink.
\end{tabular}

Fonte: Elaborado pelos autores

Depois de identificadas, as narrativas foram caracterizadas de acordo com os elementos da narrativa digital presentes em sua composição (Paul, 2007), além de sua finalidade enquanto apropriação pelo jornalismo nas mídias sociais (Rost, 2012).

Como forma de avaliar e classificar as narrativas presentes em ambientes digitas, para determinar seu efeito nos consumidores de notícias em ambiente on-line, Paul (2007) propõe a taxonomia das narrativas digitais. Um dos elementos analisados é o contexto, que, nesta pesquisa, serviu para diferenciar e classificar dois grupos de narrativas. No que se referem ao contexto, as narrativas digitais podem ser autoexplicativas ou hipermidiáticas. 
No grupo das autoexplicativas, fazem parte aquelas que trazem a informação fim, geralmente a notícia, nas Stories, sem a necessidade de links externos que complementem ou expandem o conteúdo noticiado nas mídias sociais. Já as hipermidiáticas são aquelas que, em uma ou mais postagens, é sugerido ao usuário o acesso a um link externo ao aplicativo, que geralmente o direciona ao site de notícia do veículo jornalístico. Tanto no Instagram Stories quanto no Snapchat, a indicação das postagens que apresenta links é demonstrada ao usuário na parte inferior da tela, e seu acesso se dá com o ato de deslizar a tela, feito pelo usuário.

Além do contexto da narrativa, foi possível classificá-las a partir da forma de difusão da notícia nas Stories em três tipos: reportar, recomendar, reportar e recomendar notícias (Rost, 2012; Hermida, 2012). Quando utilizadas para reportar notícias, as mídias sociais funcionam como mais um meio para produzir a informação. Já na recomendação, elas servem para indicar as notícias que estão disponíveis em outros espaços ou meios. Há ainda aquelas que reportam e recomendam notícia na mesma estrutura narrativa.

\section{NOVE TIPOLOGIAS DE NARRATIVAS JORNALÍSTICAS EM FORMATO DE STORIES}

As narrativas jornalísticas em formato de Stories são um conjunto de postagens publicadas nas Stories mídias sociais de imagens instantâneas, com o fim de informar o publica sobre um assunto noticioso. Através da observação, descrição, categorização e agrupação das postagens de perfis jornalísticos no Instagram Stories e Snapchat, foi possível propor nove diferentes tipos de narrativas, além de classificá-las, a partir da forma de difusão e do contexto narrativo.

O quadro 3 especifica quais narrativas fazem parte do grupo das autoexplicativas e das hipermidiáticas (Contexto da Narrativa), bem como quais são utilizadas para reportar; recomendar ou reportar e recomendar notícias (Forma de Difusão):

Quadro 3 - Classificação das narrativas por forma de difusão e contexto

\begin{tabular}{|c|c|c|}
\hline Forma de Difusão & Tipo de Narrativa & Contexto da Narrativa \\
\hline \multirow[t]{4}{*}{ Reportar Notícias } & Textual & \multirow{5}{*}{ Narrativas Autoexplicativas } \\
\hline & Entrevista & \\
\hline & Jornalista Selfie & \\
\hline & Nota & \\
\hline \multirow[t]{3}{*}{ Recomendar Notícias } & Convite & \\
\hline & Convite Hipermidiática & \multirow[t]{4}{*}{ Narrativas Hipermidiáticas } \\
\hline & Chamada Hipermidiática & \\
\hline \multirow[t]{2}{*}{ Reportar e Recomendar Notícias } & Textual Hipermidiática & \\
\hline & Múltiplos Formatos & \\
\hline
\end{tabular}

Fonte: Elaborado pelos autores 
Todas as narrativas que têm como forma de difusão apenas a reportagem de notícias são autoexplicativas. Isso por que elas não apresentam links externos à mídia social, portanto, trazem nas próprias Stories a notícia jornalística. Já as narrativas hipermidiáticas têm como forma de difusão a recomendação - que se dá através dos links. Há, ainda, narrativas hipermidiáticas que servem tanto para reportar como para recomendar notícias - a notícia está presente na narrativa, mas também pode ser complementada com outras ou mais informações que são acessadas em um link.

As nove tipologias de narrativas em Stories identificadas nesta pesquisa são descritas e caracterizadas a seguir.

\subsection{Narrativa Textual}

A mais básica de todas as narrativas jornalísticas em formato de Stories que tem como forma de difusão reportar notícia é a Narrativa Textual. De contexto autoexplicativo, ela é caracterizada por uma sequência de imagens, que podem ser de fotos, vídeos ou gifs, e um texto ou legenda, que, visualizadas de modo conjunto, formam uma notícia. Os principais elementos da narrativa textual são a imagem e o texto, mas também podem acompanhar hiperlinks - de geolocalização, marcação de usuário ou hashtags. Quando apresentada em mídia do tipo vídeo, esse nunca terá a presença do jornalista como apresentador da notícia em cena. Os vídeos da Narrativa Textual costumam ser cenas ou imagens gravadas que complementarão o texto da legenda. A figura 1 traz o recorte dessa narrativa no perfil @snap-expresso, no Snapchat:

Figura 1. Narrativa Textual

Fonte: Captura de tela

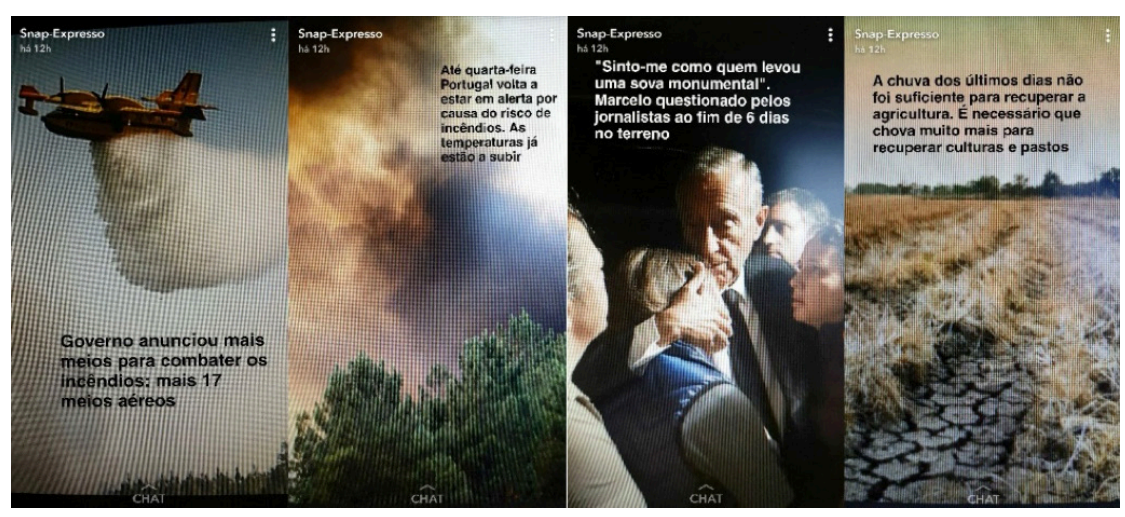

Apesar de apresentar links de geolocalização, marcação de usuário ou hashtags, a narrativa textual continua sendo autoexplicativa, e não hipermidiática. Isto porque o conteúdo disponível nestes links não está diretamente relacionado com o conteúdo do texto da narrativa apresentada nas Stories. O mesmo acontece nas outras narrativas autoexplicativas identificadas nesta pesquisa, como a Entrevista, Jornalista Selfie, Nota e Convite. 
Por se tratar de uma notícia que está sendo narrada em texto e imagens, as legendas da Narrativa Textual poderão seguir a linguagem da notícia jornalística tradicional, com uso de informações que, quando apresentadas em outros meios de comunicação, estariam presentes no lead. O motivo de focar nas principais informações da notícia é justamente a limitação do tempo e a efemeridade desses aplicativos.

\subsection{Narrativa Textual Hipermidiática}

É a versão hipermidiática da Narrativa Textual. Assim, além de apresentar aqueles elementos básicos da Narrativa Textual - textos, imagens e legendas - a Narrativa Textual Hipermidiática traz, em uma ou mais postagens, a possibilidade de acessar um link externo ao aplicativo de mídia social, que direciona o usuário ao site de notícias do veículo jornalístico. Para saber se a Narrativa Textual é hipermidiática ou não, há uma indicação na postagem a respeito da presença do hiperlink. Além da legenda na imagem (Arraste para ver mais, arraste e leia mais, etc), o Instagram e Snapchat indicam se a postagem é hipermidiática com o hiperlink na parte inferior da tela. Um exemplo da Narrativa Textual Hipermidiática está representado na Figura 2, com recorte das postagens feitas pelo @portalg1 no Instagram Stories:

Figura 2. Narrativa Textual Hipermidiática

Fonte: Captura de tela

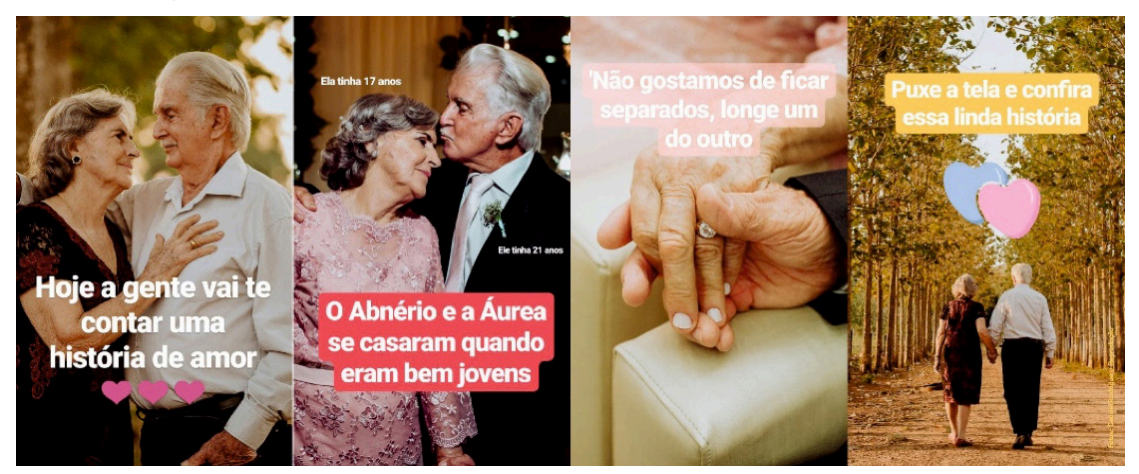

Sendo assim, a Narrativa Textual Hipermidiática tende a não apresentar a informação de forma completa para o público. Dessa maneira, a depender da pauta, poderá servir tanto para reportar quanto para recomendar as notícias. Para ler a notícia na íntegra, é necessário acessar o site externo. Essa narrativa é mais utilizada para aguçar a curiosidade do usuário em relação àquela notícia.

\subsection{Narrativa de Chamada Hipermidiática}

A Narrativa de Chamada Hipermidiática tem como único modo de difusão a recomendação de notícias, ou seja, o veículo utiliza a ferramenta para indicar as notícias que já estão publicadas em seus sites jornalísticos. Esse tipo de narrativa é formado por uma sequência de postagens com fotos, vídeos ou gifs compostas por legendas que apresentam o título ou alguma informação 
da notícia, que pode ser acessada de forma completa com o acesso ao hiperlink. A figura 3 traz o recorte dessa narrativa no perfil @uoloficial no Instagram Stories:

Figura 3. Narrativa de Chamada Hipermidiática

Fonte: Captura de tela
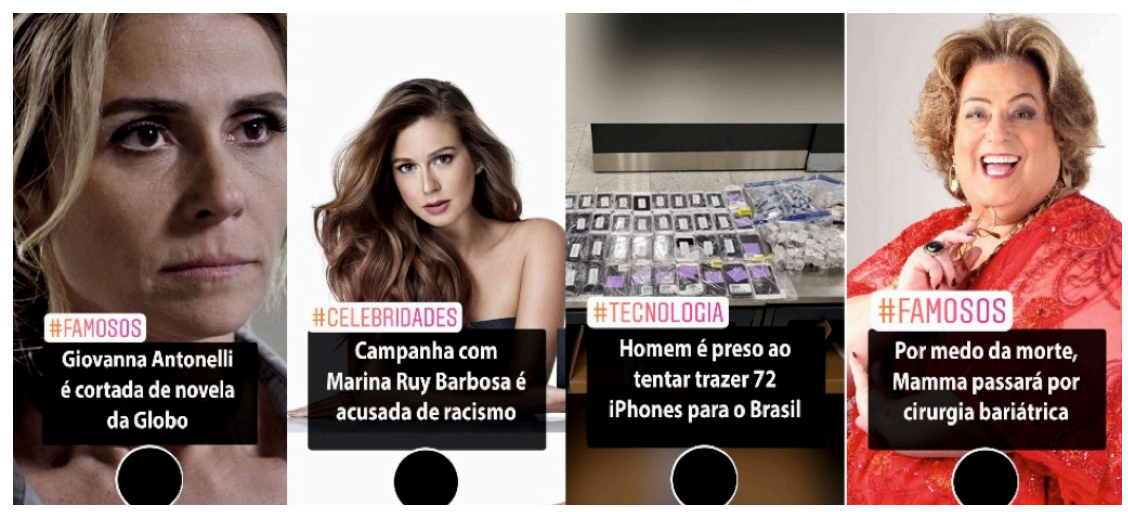

Por ter como modo de difusão a recomendação, a Narrativa de Chamada Hipermidiática não é uma narrativa que traz uma mesma notícia em uma sequência de histórias, mas apenas títulos de matérias que estão disponibilizadas nos sites dos veículos. Por isso, o texto das legendas é quase sempre estruturado no formato sujeito, verbo e ação.

\subsection{Narrativa Convite}

Neste tipo de narrativa, o jornalista grava a mensagem fazendo alguma chamada para o público: algum programa, reportagem ou notícia que serão exibidos ou estarão disponíveis em outro meio, geralmente o originário. Assim como a Narrativa de Chamada, na Narrativa Convite, não há a preocupação em apresentar a notícia completa ou parte dela, neste caso, o veículo utiliza a ferramenta somente para convidar o usuário a acompanhá-lo em outra mídia. A figura 4 traz o recorte dessa narrativa no perfil @globonews, no Instagram Stories:

Figura 4. Narrativa Convite

Fonte: Captura de tela

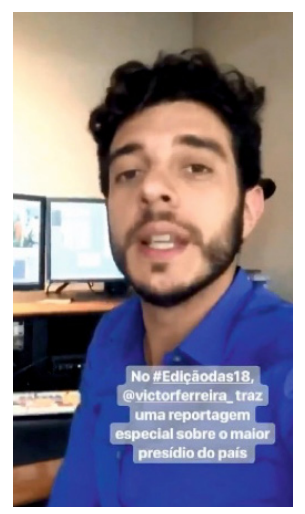


Pode ser que o jornalista traga algumas informações ou detalhes da notícia ou programa disponível na mídia originária, porém, essas irão aparecer da forma mais breve possível. É a única narrativa autoexplicativa que serve para recomendar notícias, e é comumente utilizada nos perfis jornalísticos e veículos originários da televisão. É utilizada também para convidar o público a acompanhar transmissões ao vivo de entrevistas em outras mídias sociais como o Facebook.

\subsection{Narrativa Convite Hipermidiática}

Tem as mesmas características e funções da Narrativa Convite, a diferença é a presença de hiperlinks que, quando acionados, direcionam o usuário a uma página da internet. $\mathrm{O}$ que difere a Narrativa Convite Hipermidiática da Narrativa de Chamada Hipermidiática é que na primeira, o jornalista aparece em cena, com o título de uma notícia ou pequena informação da mesma. A figura 5 traz o recorte dessa narrativa no perfil @opovoonline, no Instagram Stories:

\section{Figura 5. Narrativa Convite Hipermidiática}

Fonte: Captura de tela

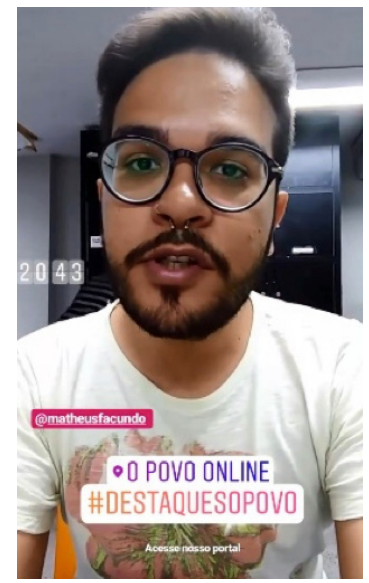

A Narrativa Convite Hipermidiática é muito utilizada para convidar o usuário a acessar a notícia no site jornalístico do veículo, com o diferencial da presença do jornalista.

\subsection{Narrativa Jornalista Selfie}

Neste tipo de narrativa, há a presença do jornalista em cena, geralmente com a câmera na modalidade selfie, cobrindo uma pauta externa da redação. É feito uma sequência de postagens que inclui introdução (passagem), imagens e cenas do acontecimento, voz do repórter em fundo com informações do fato e imagens do acontecimento (cenas com off), e, em alguns casos, a entrevista com alguma fonte (sonora). Ou seja, apresenta todos, ou grande parte, dos elementos da reportagem para a televisão. 
O temo jornalismo selfie já é empregado por alguns pesquisadores, como Maniou e Vleglis (2016), e refere-se à utilização da câmera do celular no modo selfie, ou alternando com câmera traseira, para a realização de coberturas jornalísticas, em tempo real ou não, com o fim de serem publicadas em mídias sociais que permitem a transmissão ao vivo ou a postagem de vídeos. A figura 6 traz o recorte dessa narrativa no perfil @opovoonline, no Instagram Stories:

Figura 6. Narrativa Jornalista Selfie

Fonte: Captura de tela

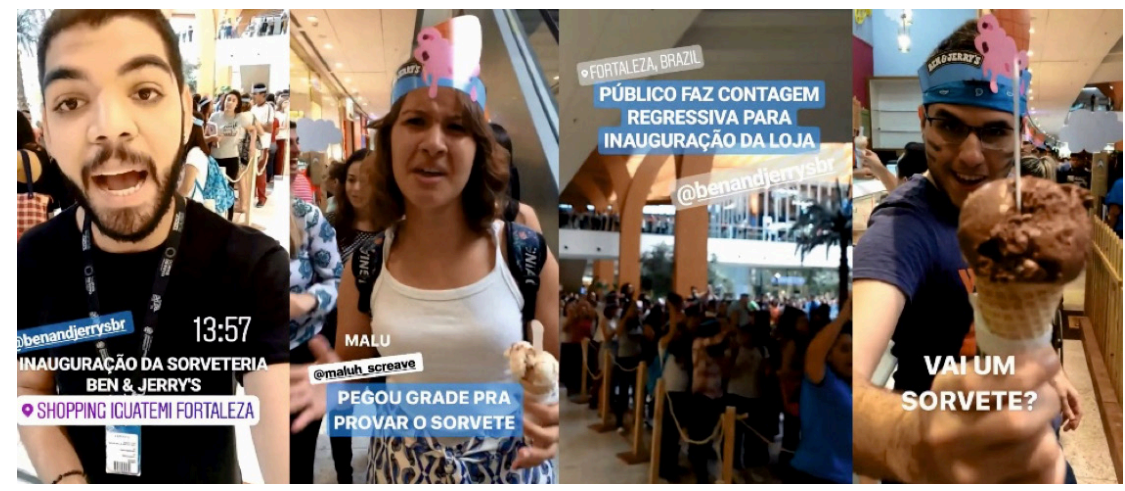

A Narrativa Jornalista Selfie tem como modo de difusão a reportagem de notícias, isto é, quando o veículo constrói uma notícia nesse formato narrativo, está utilizando a forma mais completa de se apropriar das mídias sociais de imagens instantâneas como espaço de difusão da informação. Essa narrativa é usualmente publicada durante a cobertura do acontecimento, por esse motivo, o jornalista se preocupa em trazer várias informações importantes nas postagens, que estarão dispostas nas passagens, entrevistas e notas cobertas. Portanto, é autoexplicativa e não apresenta hiperlinks que direcionam o usuário à notícia publicada no site do veículo, por exemplo, já que a narrativa já estará disponível no Instagram ou Snapchat antes mesmo do jornalista chegar à redação para redigir ou editar a versão da notícia para outras mídias.

\subsection{Narrativa de Nota}

Nessa narrativa o jornalista conta a notícia ou narra um fato, e a história é construída a partir da união de todas as postagens. Seu formato é semelhante à nota seca ou pelada do telejornalismo, onde a informação é trazida pelo jornalista sem o uso de entrevistas ou imagens com off. Na Narrativa de Nota a notícia está presente apenas na mídia social, ou seja, não há links hipermidiáticos que direcionam o usuário ao site jornalístico, tornando-as, portanto, autoexplicativas. A figura 7 traz o recorte dessa narrativa no perfil @snap-expresso, no Snapchat:

A Narrativa de Nota pode ser utilizada tanto para narrar uma informação, quanto para o jornalista tecer comentários sobre o fato jornalístico. Também pode aparecer antecedendo outras narrativas, como a Textual. 
Figura 7. Narrativa De Nota

Fonte: Captura de tela

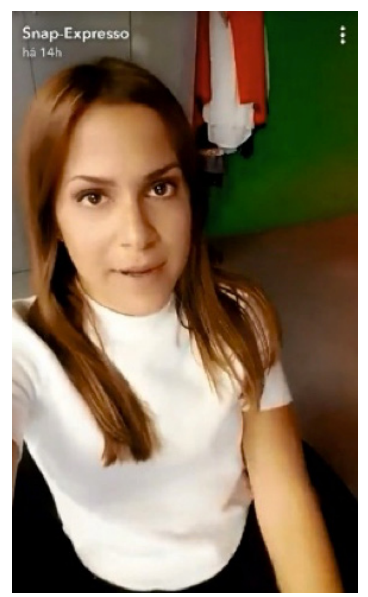

\subsection{Narrativa de Entrevista}

Como o próprio nome diz, a Narrativa de Entrevista tem como essência a entrevista jornalística. Assim como na entrevista para televisão, o veículo jornalístico utiliza as mídias sociais em formato de imagens instantâneas para construir uma narrativa formada por perguntas e respostas entre o jornalista e a fonte. A diferença é que, neste tipo de mídia social, a fonte está limitada a um tempo de 15 segundos para responder aos questionamentos. Pode ser construída de duas formas: vídeos curtos que intercalam a pergunta do jornalista com a resposta do entrevistado, ou vídeos compostos apenas com a resposta do entrevistado. Neste último caso, pode-se utilizar a ferramenta de texto para inserir as perguntas nas postagens das repostas em vídeo. A figura 8 traz o recorte dessa narrativa no perfil @cbsnews, no Instagram Stories:

\section{Figura 8. Narrativa de Entrevista}

Fonte: Captura de tela

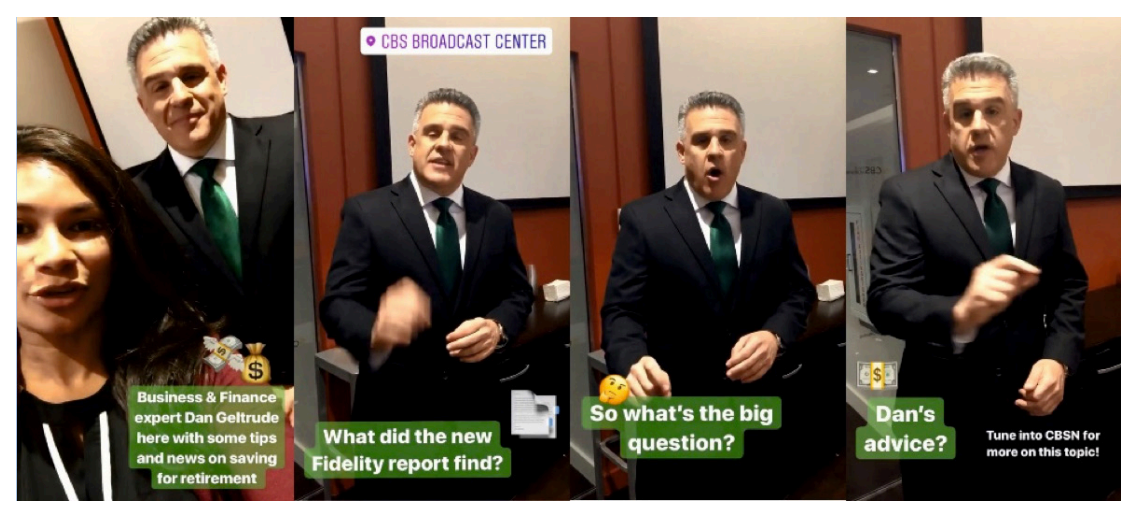

Assim como as Narrativas de Nota e Jornalismo Selfie, o conteúdo da Narrativa de Entrevista tende a ser postado logo após a gravação dos vídeos. Este caráter instantâneo da relação 
gravação e publicação das postagens faz com que não haja a necessidade de links hipermidiáticos que direcionem os usuários à informação completa.

\subsection{Narrativa de Múltiplos Formatos}

A Narrativa de Múltiplos Formatos é formada pela hibridização de várias características das outras narrativas citadas anteriormente. Nos veículos em que foi possível identificá-la, é apresentada como um quadro fixo do perfil na mídia social com nome, periodicidade, e formato padronizado. A figura 9 traz o recorte dessa narrativa no perfil @estadao, com o \#EstadãoDrops, no Instagram Stories:

Figura 9. Narrativa de Múltiplos Formatos

Fonte: Captura de tela

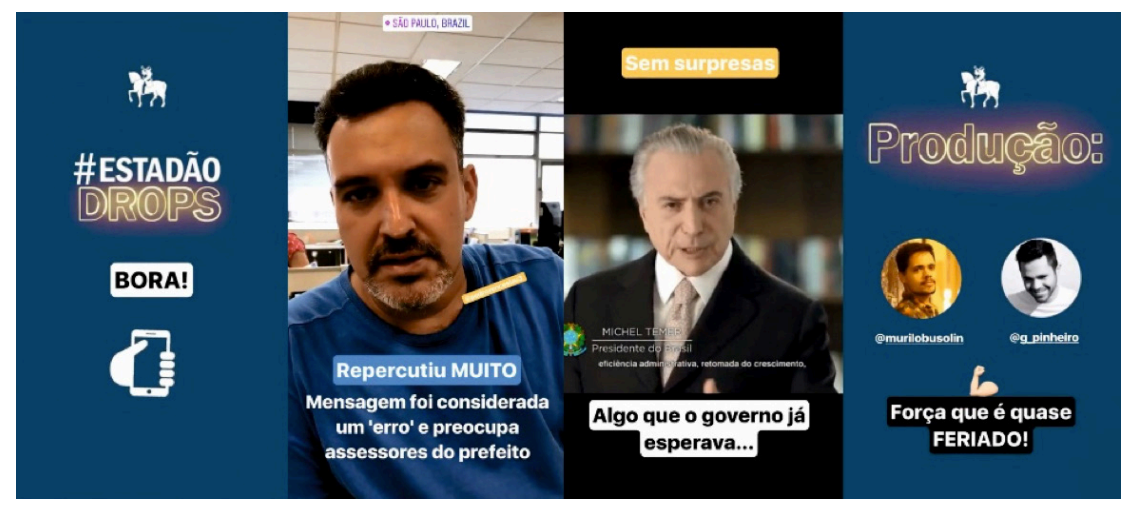

Os veículos utilizam a Narrativa de Múltiplos Formatos como uma forma mais dinâmica de difundir as notícias nos aplicativos de imagens instantâneas. A presença de vários jornalistas em cena, que se intercalam entre uma postagem e outra para recomendar ou reportar notícias, é seu principal diferencial em relação aos outros tipos de narrativas. $O$ jornalista pode aparecer para fazer um convite, uma chamada ou até mesmo notas com informações do fato em pauta naquele dia. Seu ponto mais forte é a padronização do formato e a periodicidade, o que se assemelha muito ao jornalismo produzido nos outros meios de comunicação.

\section{CONSIDERAÇÕES FINAIS}

O presente estudo não teve como objetivo estudar a audiência dessas mídias sociais. Desse modo, não se pode apontar considerações a respeito de qual tipo de narrativa é a ideal ou mais aceitável pelo público. O que se pode inferir é quais têm maior potencial interativo e multimidiático, que são pontos fortes para construir engajamento com o público. A Narrativa de Múltiplos Formatos, por agregar outros tipos de narrativas em sua estrutura, principalmente devido a figura do jornalista em cena, que interage com a mesma linguagem do público das mídias sociais, seria uma forte possibilidade de apropriação dos veículos jornalísticos nesses espaços. A Narrativa 
Jornalista Selfie também é potencial por apresentar a estrutura da reportagem, e trazer para o público a cobertura de um acontecimento diretamente do local do fato.

Pode-se concluir que, de forma geral, cada uma das nove narrativas carrega aspectos e características das notícias produzidas nos meios tradicionais, sobretudo da televisão. Elas são, portanto, uma adaptação das narrativas jornalísticas, com elementos da reportagem, da notícia, lead, entrevista, nota, chamada, dentre outros, às potencialidades e limitações das mídias sociais de imagens instantâneas: duração de tempo de cada postagem, imagens na vertical, tempo em que fica disponível para visualização (24 horas).

A Narrativa Jornalista Selfie é uma adaptação da reportagem da televisão. A Narrativa de Nota é construída sob a mesma fórmula da nota pelada do telejornalismo, assim como a entrevista. $\mathrm{O}$ texto da Narrativa Textual e Textual Hipermidiática é construído sob a base do lead jornalístico. Já as Narrativas de Chamada Hipermidiática e Convite Hipermidiática carregam a função de recomendação do jornalismo feito em outras mídias sociais, como Twitter e Facebook.

A mais diferenciada é Narrativa de Múltiplos Formatos, que é essencialmente formada a partir de potencialidades oferecidas por esse tipo de mídia social. O produtor constrói uma espécie de jornal multimídia, feito tanto para difundir quanto para recomendar notícias no meio digital, e seu ponto forte é a presença de vários jornalistas da redação, que interagem entre si. Isso reforça o potencial jornalístico e narrativo desses espaços para a construção de conteúdo informativo para o público.

Se a atividade profissional dos jornalistas diz respeito à produção de narrativas, utilizar as Stories para noticiar informações não seria algo improvável. Ao contrário, aplicativos de mídias sociais de imagens instantâneas são potenciais ferramentas para o jornalismo construir narrativas diversificadas. O público da internet está cada vez mais presente nesses espaços, ajudando a legitimar novas tendências no mercado. Neste sentido, é a partir da diversificação e experimentação de formatos inovadores que o jornalismo poderá chegar até seus públicos, cada vez mais disperso no ambiente on-line.

É necessário deixar claro que a discursão explorada nesta pesquisa representa apenas uma parte das possibilidades de estudos envolvendo as apropriações do jornalismo pelas mídias sociais de imagens instantâneas. Ao longo do desenvolvimento, puderam ser identificadas algumas possibilidades de melhoria e de continuação a partir de futuras pesquisas, as quais incluem: estudo dos assuntos que são comumente pautados nas narrativas em formato de Stories, estudo de recepção, identificando quais narrativas despertam mais o interesse do público em continuar assistindo o vídeo ou não; estudo organizacional, a fim de investigar como a apropriação pelo jornalismo por esse tipo específico de mídia social tem transformado os modos de produção da notícia nas redações jornalísticas, dentre outros.

Diante dessas considerações, espera-se que esse estudo seja útil não só para comunidade acadêmica, como fonte de estudo ou impulso para produção de novas investigações e para aflorar 
discursões sobre a temática nos cursos de comunicação, mas também ao mercado jornalístico. A expectativa é de que os veículos de comunicação e os jornalistas, que por algum motivo não utilizam essas ferramentas, possam pensar na possibilidade de apropriar-se da diversidade de narrativas aqui apresentadas.

\section{NOTAS}

${ }^{1}$ Até o final desta pesquisa, só era possível adicionar links às postagens naqueles perfis com mais de dez mil seguidores.

${ }^{2}$ Para os veículos do jornalismo impresso, foi considerado o número de tiragem diária dos jornais; no caso da televisão, dados de audiência dos veículos de comunicação, e os nativos online, o número de acessos por ano

${ }^{3}$ Através de algoritmos do próprio aplicativo, a funcionalidade sugestões indica para o usuário, logo após que ele segue um perfil, outros perfis que fazem parte da mesma categoria. Nesse caso, quando se segue o perfil de um veículo jornalístico, são sugeridos outros perfis jornalísticos para seguir

\section{REFERÊNCIAS}

Bardin, L. (2009). Análise de Conteúdo. Lisboa: Edições 70.

Bayer, J et al. (2015). Sharing the Small Moments: Ephemeral Social Interaction on Snapchat. Information Communication and Society, 16(7), 956-977.

Bradshaw, P; Maseda, B. (2016). Snapchat para periodistas. [S. I.]: Leanpub.

Flores-Vivar, J.M. (2012). Convergencia de las redes sociales en internet y en la telefonía móvil. In: Cébrian-Herreros, M; Flores-Vivar, J.M (Orgs). Innovaciones periodísticas en las redes sociales (21-38). Madrid: Universidad Complutense de Madrid.

García-De-Torres, E. et al. (2011). Uso de Twitter y Facebook por los medios iberoamericanos. El Profesional de La Información, 11(20), 611-620.

Hermida, A. (2012). Social Journalism: Exploring how Social Media is Shaping Journalism. The Handbook Of Global Online Journalism, 309-328.

Herrero-Curiel, E. (2012). El periodismo en el siglo de las redes sociales. Vivat Academia, (117), 11131128.

Jungblut, G. (2017). Como usar o Instagram Stories em estratégias de marketing (e por que você não pode ficar fora dessa... In shopify. Recuperado em 10 de outubro de 2017 em https://goo.gl/U8bLTj

Kaplan, A. M.; Haenlein, M. (2009). Users of the world, unite! The challenges and opportunities of Social Media. Business Horizons, 53(1), 59-68.

Lopes, M.I.V. (2003). Pesquisa em Comunicação. São Paulo: Loyola. 
Maniou, T; Veglis, A. (2016). 'Selfie Journalism': Current Practices in Digital Media. Studies In Media And Communication, 4(1), 111-118.

Mendéz, M.C (2012). Qué son los nuevos medios y los medios sociales. In: Tascón, Mario (Org.), Escribir en Internet: guía para los nuevos medios y las redes sociales (14-16). [s.i]: Galaxia Gutenberg.

Pacheco, Y.R.Q. (2014). Las redes sociales como herramientas del periodismo digital. Cultura, 28(0), 279303. Recuperado em 29 de abril de 2017 em https://goo.gl/uECXKw

Paul, N. (2007). Elementos das narrativas digitais. In: Ferrari, P. (Org.). Hipertexto, hipermídia: as novas ferramentas da comunicação digital (121-140). São Paulo: Contexto.

Recuero, R. (2009). Redes sociais na internet, difusão de informação e jornalismo: elementos para discussão. Metamorfoses jornalísticas, 2, 1-15.

Rost, A. (2012). Modelos de uso y gestión de redes sociales en el Periodismo. In Trabajo presentado en el IV Congreso Internacional de Ciberperiodismo y Web (Vol. 2). Recuperado em 10 de outubro de 2017 em https://goo.gl/aXi1Vs 